\title{
Changes in intensity of high temporal resolution precipitation extremes in Romania: implications for Clausius-Clapeyron scaling
}

\author{
Aristita Busuioc*, Madalina Baciu, Traian Breza, Alexandru Dumitrescu, \\ Cerasela Stoica, Nina Baghina
}

National Meteorological Administration, Sos. Bucuresti-Ploiesti 97, Sect.1, Bucharest 013686, Romania

\begin{abstract}
We propose a new index for quantifying the maximum rain intensity (IMAX) within a rainfall event. The goal of this paper is 2 -fold: first, to analyse the characteristics of variability (trends, change points) for maximum values of this index calculated for spring (April-May), summer (June-August) and autumn (September-October) in comparison with other 2 precipitation indices (daily maximum and total amount). Secondly, to investigate the scaling of the IMAX high percentiles with temperature and compare the results to hourly precipitation extremes. The analysis was carried out at 6 Romanian stations over the period 1966-2007, extended over 1902-2007 for one station. Our results revealed a statistically significant increase of IMAX over the 20th century (intensified over the second half), in contrast with no significant trends in the other 2 precipitation indices. On the other hand, an opposite phase between IMAX variability and its corresponding duration (e.g. shorter durations correspond to higher intensities) was noted. Regarding the scaling behaviour of the IMAX percentiles, there was a difference between summer and spring/autumn. In summer, the 90th and 99th percentiles showed a Clausius-Clapeyron (CC) scaling for temperatures between 14 and $26^{\circ} \mathrm{C}$ and then a decrease, while the 99.9th percentile showed a super-CC scaling for temperatures lower than $18^{\circ} \mathrm{C}$ and then a decrease. The spring and autumn 90th and 99th percentiles showed an approximate $2 \mathrm{CC}$ scaling for temperatures ranging from $8-20^{\circ} \mathrm{C}$. The 99.9 th percentile exhibited a scaling close to the $2 \mathrm{CC}$ relationship for a temperatures range of $12-18^{\circ} \mathrm{C}$ (spring) and then a decrease, while the autumn 99.9th percentile exhibited a dependence close to 2CC scaling for temperatures $<18^{\circ} \mathrm{C}$ and then a scaling close to CC. Comparing these results with those referring to hourly and daily precipitation extremes, we conclude that the magnitude of the CC scaling in Romania is mainly dependent on the temporal scale of the extreme precipitation event, storm intensity and season. The proposed index (IMAX) is more sensitive to temperature increases than the hourly and daily extremes, and therefore it is more appropriate to quantifying the climate signal related to intense precipitation events in a warmer climate.
\end{abstract}

KEY WORDS: Extreme precipitation index $\cdot$ Temperature $\cdot$ Scaling $\cdot$ Clausius-Clapeyron relation Trends $\cdot$ Romania

\section{INTRODUCTION}

Short duration and high intensity rainfalls have a large impact on society, with one of the greatest effects being urban flooding. There is observational evidence that extreme precipitation intensity has in-

${ }^{*}$ Corresponding author: busuioc@meteoromania.ro creased in many places (Trenberth et al. 2003, Lenderink et al. 2011, Benestad 2013, O'Gorman 2015, Molnar et al. 2015) and climate simulations have revealed that this characteristic will be maintained and even intensified under future global warming (Pall et al. 2007, Allan \& Soden 2008, Scoccimarro et restricted. Authors and original publication must be credited. 
al. 2013, Ban et al. 2015, Chan et al. 2015). This behaviour is supported from a theoretical point of view by the so-called Clausius-Clapeyron relation (hereafter referred to as ' $\mathrm{CC}$ scaling'), which states that atmospheric humidity will increase at a rate that follows the saturation vapor pressure dependency on temperature (a rate of $\sim 6-7 \%{ }^{\circ} \mathrm{C}^{-1}$ ), under conditions of constant relative humidity (Trenberth et al. 2003, Pall et al. 2007, Westra et al. 2014, Blenkinsop et al. 2015, Molnar et al. 2015). A recent review on this topic is presented by $\mathrm{O}^{\prime}$ Gorman (2015).

However, recent studies have revealed that the relationship between precipitation extremes and temperature is very complex and depends on many factors, such as storm duration (Hardwick-Jones et al. 2010, Westra et al. 2014, Wasko et al. 2015), season (Ban et al. 2015, Blenkinsop et al. 2015), storm type (Berg et al. 2013, Molnar et al. 2015), microphysics (Singh \& O'Gorman 2014), regional atmospheric stability (Loriaux et al. 2013) and large-scale circulation (Blenkinsop et al. 2015). In some areas, a strong difference between coastal (showing dependence close to CC scaling) and inland regions (showing a superCC scaling) has been found (Panthou et al. 2014). The intensity of sub-daily precipitation extremes is more sensitive to temperature changes compared to the intensity of daily extremes (Westra et al. 2014). CC scaling can be also affected by local and regional factors that can limit moisture availability, especially in mountain valleys (Molnar et al. 2015).

Future projected changes in precipitation extremes under global warming can be supplied by global (GCMs) or regional (RCMs) climate models that currently operate with spatial resolutions larger than 100 or $10 \mathrm{~km}$, respectively. Due to their still coarse spatial resolution, even state-of-the-art RCMs are not able to fairly reproduce short-duration precipitation extremes (convective precipitation) since some subgrid processes (e.g. deep convection) triggering such phenomena are parameterized through convection schemes (Prein et al. 2015). A solution to this problem is suggested by use of so-called 'convection-permitting models' (CPMs) (Prein et al. 2015, O'Gorman 2015).

Studies investigating the observed extreme rainfall intensity-temperature relationship have been mainly based on fixed temporal resolution precipitation data. A new challenge is an analysis carried out on storm events compared to fixed data (Wasko \& Sharma 2015), but the difficulty with such a study is the lack of data regarding the internal characteristics of rainfall event progress (e.g. fractions of various intensities and durations).
Such a study is presented in this paper, where a new index quantifying the extreme precipitation intensity of rainfall events is proposed. The goal of this paper is 2-fold. First, to analyse the characteristics of variability (long-term trends, change points) for maximum values of this index calculated for spring (April-May), summer (June-August) and autumn (September-October) in comparison to 2 other precipitation indices, namely daily maximum and total amount. Second, to investigate the scaling of its high percentiles (90th to 99.9th) with temperature. The analysis was done at 6 stations in Romania. A possible connection between the scaling of this index with temperature and the CC scaling was investigated. Busuioc et al. (2016) carried out a similar analysis for the high percentiles of hourly and daily precipitation at the same stations. They found that scaling was less evident for daily extremes, while the hourly extremes exhibited a scaling close to $\mathrm{CC}$ or $2 \mathrm{CC}$ relation, depending on the storm intensity. Corroborating these results with that of the present study, we hoped to find the most sensitive temporal scale of precipitation extremes to temperature increase, at least for the Romanian area.

\section{DATA AND METHODS}

Measurements regarding the internal characteristics of a rainfall event progress (e.g. periods of various intensities and durations) based on graphical records (pluviograph) were used in this study to identify the period (in minutes) with the highest rainfall intensity. In this paper, a rainfall event is defined as starting with non-zero precipitation and ending when the rainfall stops, e.g. zero precipitation amount accumulated in the previous period.

As far as we know, these types of records are seldom used in climate research. Compared to the classical rainfall data set of fixed temporal resolution (sub-hourly, hourly, daily) that are usually used to investigate the observed relationship of precipitation extremes with temperature (termed 'scaling'), we propose an index quantifying the real highest rain intensity within a rainfall event, which can be derived from such data. We hypothesize that this intensity is more sensitive to temperature increases compared to the mean precipitation intensity within a rainfall event or to the maximum rainfall intensity over a fixed duration (e.g. daily or hourly). A similar idea was recently used by Wasko \& Sharma (2015) through the analysis of precipitation measurements at a 6 min resolution. However, they used equal 
duration periods within a storm (e.g. 6 min). The division of a rainfall record into fixed duration subintervals could miss the real highest rain intensity and associated duration due to the selection procedure, as we explain in the following section. Only measurements based on a continuous rainfall record (as is the case of pluviograph records used in this study) allow identification of the highest rainfall intensity at the lowest temporal resolution of $1 \mathrm{~min}$.

The types of records mentioned above at 6 weather stations across Romania representing various physical-geographical conditions (see Fig. S1 in the Supplement at www.int-res.com/articles/suppl/c072p239 _supp.pdf) were used in this study. We note that these stations do not cover the entire complexity of the Romanian climate (e.g. mountain areas are not included), due to the current lack of such data. These data sets are available only for liquid precipitation, which usually occurs between April and October for Romanian climate conditions. Each rainfall event was divided into intervals of approximately constant intensity $\left(\mathrm{mm} \mathrm{min}^{-1}\right)$. To explain how these intervals were defined and how the intensity for each interval was calculated, Fig. 1 presents an example of a raw graphical record regarding rainfall from 2 June 2000

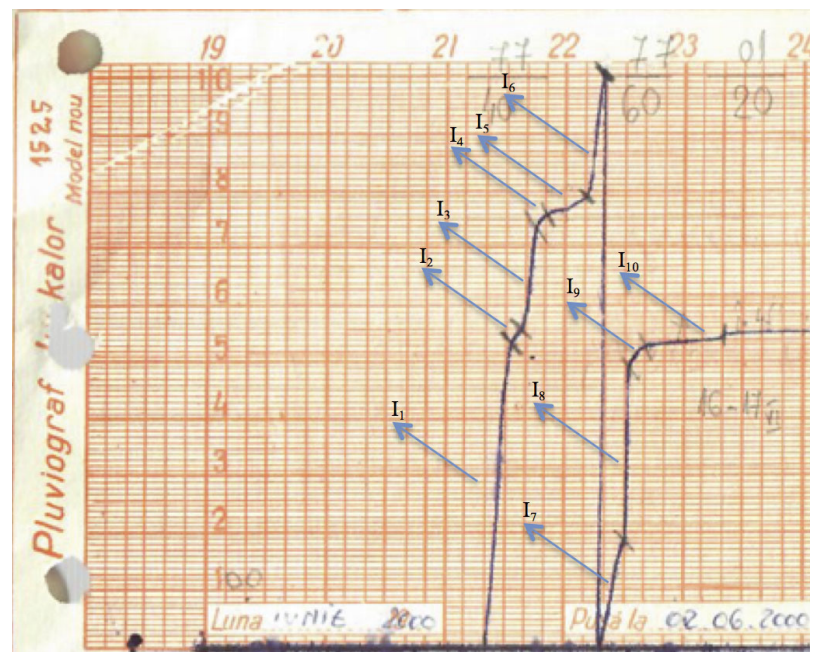

Fig. 1. Graphical record (pluviograph) of the rainfall event from 2 June 2000 at Constanta station showing the temporal variation (horizontal divisions of $10 \mathrm{~min}$; hours are displayed at the top of the graph) of precipitation amount (vertical divisions of $0.1 \mathrm{~mm}$; integer numbers are marked). Delimitation of each interval when the slope of the precipitation temporal variation curve changes is marked and these intervals are presented in Table 1. Since rainfall exceeds the upper limit of the graph at $10 \mathrm{~mm}$, the graph restarts from the beginning (at $0.0 \mathrm{~mm}$ ) but the recorded precipitation amount is cumulated to the previous one when this graphical record is numerically deciphered by the trained meteorological observer, so that a continuous record of the rainfall is obtained at Constanta station, showing the curve of the precipitation temporal variation within the rainfall event. Time is displayed on the horizontal axis, while the precipitation amount is represented on the vertical. The moment when the curve slope changes (see Fig. 1) was marked by a trained meteorological observer, along with the precipitation amount recorded at that time. This way, the intervals $I_{j}, j=$ $1, \ldots, \mathrm{n}$ (where $\mathrm{n}$ is the number of intervals) with approximately constant intensity $\left(\mathrm{mm} \mathrm{min}^{-1}\right)$ were delimited based on the assumption that an approximately constant slope of the precipitation temporal variation curve over each interval $I_{j}$ leads to an approximately uniform precipitation variation over that interval. Consequently, the precipitation intensity $\left(\mathrm{mm} \mathrm{min}{ }^{-1}\right)$ is approximately constant over each $I_{j}$. To avoid repetition of the word 'approximately', it will be omitted in the following. The next step is to calculate the following information for each interval $I_{j}$ : duration $\left(D_{j}\right.$, in minutes; the difference between the time of the end and that of the beginning), precipitation amount $\left(P_{j}\right)$ over each interval (difference between the amount recorded at the end and beginning of each interval, respectively) and rainfall intensity $\left(\mathrm{IST}_{j}\right)$ calculated as a ratio between $P_{j}$ and $D_{j}$. The information presented above is summarised in Table 1, showing a complete view of the internal characteristics of the rainfall event. Only this type of record allows identifying time intervals with about the same rainfall intensity per minute, and therefore the maximum precipitation intensity on a temporal scale of 1 min can be obtained; as far as we know, this has not been presented in any other previous papers.

The interval of analysis was 1966-2007, while for the Bucuresti-Filaret station these data sets were available over a longer interval (1902-2007). The maximum intensity for each rainfall event (IMAX) is defined as follows:

$$
\mathrm{IMAX}=\max \left\{\mathrm{IST}_{j}, j=1, \ldots, \mathrm{n}\right\}
$$

where $\mathrm{n}$ represents the number of sub-intervals $I_{j}$ with constant intensity $\operatorname{IST}_{j}(j=1, \ldots, \mathrm{n})$ during a rainfall event. In the example presented above, IMAX = 3.0 (bold value in Table 1) and the corresponding duration (hereafter noted by DIMAX) is 1 min: here the duration of 1 min corresponding to IMAX is coincidentally equal to the temporal scale of the $\mathrm{IST}_{j}$ $\left(\mathrm{mm} \mathrm{min}{ }^{-1}\right)$. This intensity corresponds to the interval $I_{8}$ between 22:30 and 22:31 $\mathrm{h}$. This procedure was applied for all rainfall events at each station. Therefore, the time series of IMAX and the corresponding DIMAX for all rainfall events at each station was retained for the analysis presented in this study. 
Table 1. Temporal variation of precipitation amount during the rainfall event recorded on 2 June 2000 at Constanta station. The rainfall is divided in 10 intervals of constant intensity $\left(\mathrm{mm} \mathrm{min}^{-1}\right)$. These intervals $\left(I_{j}, j=1, \ldots, 10\right)$ are delimited by the time ( $t$, second column) when the slope of the temporal variation curve of the precipitation amount recorded by the pluviograph changes. The precipitation amount recorded at the end of each $I_{j}$ is noted (3rd column). Fig. 1 shows the graphical representation of this rainfall event and the delimitation of each interval. Duration $\left(D_{j}\right)$ and total precipitation amount $\left(P_{j}\right)$ recorded over each interval $\left(I_{j i}\right.$ calculated as the difference between precipitation amounts recorded at the end of each interval $I_{j}$ and the end of previous interval $I_{j-1}$ ) are presented. Rainfall intensity ( $\mathrm{IST}_{j}$ ) is calculated as a ratio between $P_{j}$ (5th column) and corresponding $D_{\mathrm{j}}$ (4th column). The row corresponding to the maximum intensity (IMAX) shown in bold

\begin{tabular}{|ccccccc|}
\hline$I_{j}$ & $t$ & $\begin{array}{c}\text { Precipitation } \mathrm{r} \\
(\mathrm{mm})\end{array}$ & $\begin{array}{c}D_{j} \\
(\mathrm{~min})\end{array}$ & $\begin{array}{c}P_{j} \\
(\mathrm{~mm})\end{array}$ & $\begin{array}{c}\mathrm{IST}_{j} \\
\left(\mathrm{~mm} \mathrm{~min}^{-1}\right)\end{array}$ & Comment \\
\hline & $21: 20 \mathrm{~h}$ & 0.00 & & & & Rainfall start \\
$I_{1}$ & $21: 33 \mathrm{~h}$ & 5.30 & 13 & 5.30 & 0.41 & \\
$I_{2}$ & $21: 38 \mathrm{~h}$ & 5.60 & 5 & 0.30 & 0.06 & \\
$I_{3}$ & $21: 45 \mathrm{~h}$ & 7.40 & 7 & 1.80 & 0.26 & \\
$I_{4}$ & $21: 50 \mathrm{~h}$ & 7.60 & 5 & 0.20 & 0.04 & \\
$I_{5}$ & $22: 10 \mathrm{~h}$ & 7.90 & 20 & 0.30 & 0.02 & IMAX \\
$I_{6}$ & $22: 20 \mathrm{~h}$ & 10.00 & 10 & 2.10 & 0.21 & Pluviograph restart \\
$I_{7}$ & $22: 30 \mathrm{~h}$ & 11.90 & 10 & 11.90 & 1.19 & End of rainfall \\
$I_{8}$ & $\mathbf{2 2 : 3 1 ~ \mathbf { ~ }}$ & $\mathbf{1 4 . 9 0}$ & $\mathbf{1}$ & $\mathbf{3 . 0 0}$ & $\mathbf{3 . 0 0}$ & \\
$I_{9}$ & $22: 40 \mathrm{~h}$ & 15.30 & 9 & 0.40 & 0.04 & \\
$I_{10}$ & $23: 20 \mathrm{~h}$ & 15.50 & 40 & 0.20 & 0.01 & . \\
\hline
\end{tabular}

(spring, summer, autumn) maximum values and corresponding DIMAX were computed and compared to the corresponding values of another extreme precipitation index based on the daily amount (e.g. maximum daily amount, PP24) and total precipitation amount (PP). In this paper, spring months refer to April-May, while autumn refers to September-October, considering the availability of graphical rainfall records as presented above. Summer months are June-August. The statistical significance level of the linear trend and shift was estimated by the nonparametric tests Mann-Kendall (Kulkarni \& von Storch 1995) and Pettitt (Pettitt 1979), respectively. Secondly, an investigation of the relationship between the highest IMAX percentiles (90th, 99th and 99.9th) and daily air temperature was carried out to find a possible connection with the $\mathrm{CC}$ scaling.

To reach the second objective, a

Note that delimitation of the intervals $I_{j}$ and the corresponding $D_{j}$ and $P_{j}$ were subjectively estimated by a trained meteorological observer and therefore are subject to human errors. The rainfall intensity for each interval $\mathrm{IST}_{j}$ and IMAX for each rainfall event are calculated automatically through a computing programme, but they depend on $D_{j}$ and $P_{j}$ used as inputs into that programme. Some qualitative verification was carried out as follows: comparison between the daily precipitation amount derived from the graph records (pluviograph) as presented above and those derived from measurements made with rain gauges were performed, and large differences were analysed by verifying the data numerically deciphered from raw records on pluviograph; some outliers of IMAX and corresponding DIMAX (identified in the temporal variation of annual maximum values) have also been verified with raw data. As will be presented below, the results obtained in this paper are coherent from one station to another showing similar features. Therefore, we conclude that even if some human error may be possible in the original data, the final results are not significantly influenced.

The IMAX values and their corresponding durations (DIMAX) for all rainfall events at the 6 stations were analysed in 2 ways corresponding to the main 2 objectives of this paper. First, the linear trends and shifts in the mean for the time series of IMAX seasonal technique similar to Lenderink \& van Meijgaard (2008) was used. This technique was also used by Busuioc et al. (2016) to investigate the validity of CC scaling for hourly and daily precipitation extremes at 9 Romanian stations (including the 6 considered in this study). The IMAX data for all rainfall events at each station were divided into bins of $2{ }^{\circ} \mathrm{C}$ width in terms of daily mean temperature. By using daily mean temperatures, the high temporal variability during a day is avoided.

The analysis was performed by combining all data over the entire country. This technique allows avoiding as much as possible the influence of local factors on extreme precipitation behaviour while retaining enough events to assess the percentiles (especially the 99.9th). Considering the fact that the CC scaling depends, among other factors, on the storm type (stratiform or convective), the analysis was carried out for each season. Rainfall in Romania is mainly of a convective type in summer, while in spring and autumn, stratiform rainfall prevails. Considering the small number of events in spring and autumn, the results referring to the combined data over these seasons are also presented. The 90th, 99th and 99.9th percentiles for each bin were computed and their dependence on temperature was compared to the CC $(\sim 7 \%$ increase per temperature degree rise) and $2 \mathrm{CC}$ ( $\sim 14 \%$ increase per temperature degree rise) scaling. 


\section{RESULTS}

\subsection{Observed changes in extreme rainfall intensity in Romania}

Table 2 shows the linear trend of the IMAX and DIMAX indices compared to PP24 and PP over the common period 1966-2007 (6 stations) and the long period 1902-2007 (Bucuresti-Filaret). All time series were standardized, following the procedure presented by Busuioc et al. (2015), to be compared with each other. Over the shorter period, IMAX generally exhibits an increasing trend compared to DIMAX (decreasing) but the trends are statistically significant at the $5 \%$ level only at a few stations. Since the results could be affected by the short duration of the time series, a similar analysis over more than $100 \mathrm{yr}$ (1902-2007) at Bucuresti-Filaret station was carried out and the same conclusion was found. In this case, a statistically significant increase for IMAX was found in contrast to PP24 and PP (showing no significant trend) (Table 2). This result suggests different longterm variability behaviour of IMAX in contrast to PP and PP24. This conclusion is supported by the analysis of the correlation coefficient between IMAX and PP/PP24, showing much lower values (or even no statistical significance) in contrast to the higher and statistically significant correlations between PP and PP24 (Table 3). Fig. 2 shows, as an example, the temporal variability of IMAX, PP and PP24 at BucurestiFilaret station for spring, summer and autumn.

It can be seen that, while PP and PP24 exhibit a coherent variability with each other, IMAX shows different characteristics - especially during the most recent decades in summer, when the other indices show a decrease while IMAX exhibits a significant

Table 2. Trend in 10 years of standardized precipitation indices over the short (1966-2007) and long period (1902-2007) for 3 seasons: spring (April-May), summer (June-August) and autumn (September-October). Bold values show statistically significant trends and change points (at the $5 \%$ level). The change points and associated arrows (indicating upward or downward shifts) for Bucuresti-Filaret are also included. IMAX: maximum intensity of rainfall event; DIMAX: duration of IMAX; PP24: maximum daily precipitation; PP: total precipitation

\begin{tabular}{|c|c|c|c|c|c|c|c|c|c|c|c|c|}
\hline \multirow[t]{2}{*}{ Station } & \multicolumn{4}{|c|}{ Spring } & \multicolumn{4}{|c|}{ — Summer } & \multicolumn{4}{|c|}{ - Autumn } \\
\hline & IMAX & DIMAX & PP24 & $\mathrm{PP}$ & IMAX & DIMAX & PP24 & PP & IMAX & DIMAX & PP24 & PP \\
\hline \multicolumn{13}{|l|}{ 1966-2007 } \\
\hline Bucuresti Filaret & 0.15 & -0.24 & 0.02 & -0.09 & 0.36 & -0.32 & -0.17 & -0.11 & -0.08 & -0.23 & 0.29 & 0.18 \\
\hline Constanta & 0.24 & -0.27 & -0.03 & 0.02 & 0.18 & -0.08 & 0.16 & 0.09 & 0.24 & -0.27 & 0.15 & 0.25 \\
\hline Tecuci & 0.11 & -0.25 & 0.00 & -0.12 & 0.21 & -0.09 & -0.09 & -0.02 & 0.26 & -0.31 & 0.21 & 0.14 \\
\hline Drobeta Tr Severin & -0.11 & -0.18 & -0.13 & -0.15 & -0.17 & 0.0 & 0.01 & -0.02 & 0.07 & -0.02 & 0.11 & 0.01 \\
\hline Oradea & 0.12 & 0.09 & -0.03 & 0.06 & -0.02 & 0.08 & -0.02 & -0.05 & 0.06 & 0.14 & 0.11 & 0.11 \\
\hline Sibiu & 0.07 & -0.18 & -0.09 & -0.10 & -0.08 & -0.14 & 0.12 & -0.05 & 0.06 & 0.0 & 0.08 & 0.08 \\
\hline \multicolumn{13}{|l|}{$1902-2007$} \\
\hline Bucuresti Filaret & $\begin{array}{c}0.10 \\
1961 \uparrow\end{array}$ & $\begin{array}{c}-0.08 \\
1961 \downarrow\end{array}$ & 0.02 & 0.01 & $\begin{array}{c}0.12 \\
1961 \uparrow\end{array}$ & $\begin{array}{c}-0.06 \\
\mathbf{1 9 8 7} \downarrow\end{array}$ & -0.04 & 0.0 & $\begin{array}{c}0.08 \\
1960 \uparrow\end{array}$ & $\begin{array}{c}-0.07 \\
1964 \downarrow\end{array}$ & 0.06 & 0.04 \\
\hline
\end{tabular}

Table 3. Correlation between various standardized precipitation indices over short period (1966-2007; 6 stations) and long period (1902-2007; Bucuresti-Filaret). Bold values are statistically significant at the $5 \%$ level. See Table 2 for abbreviation definitions

\begin{tabular}{|c|c|c|c|c|c|c|c|c|c|c|c|c|}
\hline \multirow[t]{2}{*}{ Station } & \multicolumn{4}{|c|}{ Spring } & \multicolumn{4}{|c|}{ Summer } & \multicolumn{4}{|c|}{ Autumn } \\
\hline & $\begin{array}{l}\text { IMAX- } \\
\text { PP }\end{array}$ & $\begin{array}{l}\text { IMAX- } \\
\text { PP24 }\end{array}$ & $\begin{array}{l}\text { PP- } \\
\text { PP24 }\end{array}$ & $\begin{array}{l}\text { IMAX- } \\
\text { DIMAX }\end{array}$ & $\begin{array}{l}\text { IMAX- } \\
\text { PP }\end{array}$ & $\begin{array}{l}\text { IMAX- } \\
\text { PP24 }\end{array}$ & $\begin{array}{l}\text { PP- } \\
\text { PP24 }\end{array}$ & $\begin{array}{l}\text { IMAX- } \\
\text { DIMAX }\end{array}$ & $\begin{array}{c}\text { IMAX- } \\
\text { PP }\end{array}$ & $\begin{array}{l}\text { IMAX- } \\
\text { PP24 }\end{array}$ & $\begin{array}{l}\text { PP- } \\
\text { PP24 }\end{array}$ & $\begin{array}{l}\text { IMAX- } \\
\text { DIMAX }\end{array}$ \\
\hline \multicolumn{13}{|l|}{ 1966-2007 } \\
\hline Bucuresti Filaret & 0.39 & 0.29 & 0.86 & -0.47 & 0.39 & 0.34 & 0.70 & -49 & 0.20 & 0.16 & 0.91 & -0.44 \\
\hline Constanta & -0.08 & 0.04 & 0.79 & -0.46 & 0.62 & 0.69 & 0.84 & -48 & 0.17 & 0.30 & 0.77 & -0.41 \\
\hline Tecuci & 0.51 & 0.31 & 0.57 & -0.44 & 0.43 & 0.25 & 0.70 & -39 & 0.51 & 0.58 & 0.91 & -0.44 \\
\hline Drobeta $\operatorname{Tr}$ Severin & 0.17 & 0.26 & 0.66 & -0.53 & 0.17 & 0.06 & 0.71 & -50 & 0.36 & 0.24 & 0.87 & -0.55 \\
\hline Oradea & 0.13 & 0.18 & 0.67 & -0.41 & 0.24 & 0.24 & 0.78 & -34 & 0.37 & 0.46 & 0.81 & -0.42 \\
\hline Sibiu & 0.10 & 0.21 & 0.64 & -0.34 & 0.02 & -0.10 & 0.54 & -21 & 0.41 & 0.51 & 0.75 & -0.38 \\
\hline \multicolumn{13}{|l|}{$1902-2007$} \\
\hline Bucuresti-Filaret & 0.23 & 0.20 & 0.74 & -0.52 & 0.24 & 0.09 & 0.58 & -0.47 & 0.31 & 0.24 & 0.87 & -0.34 \\
\hline
\end{tabular}



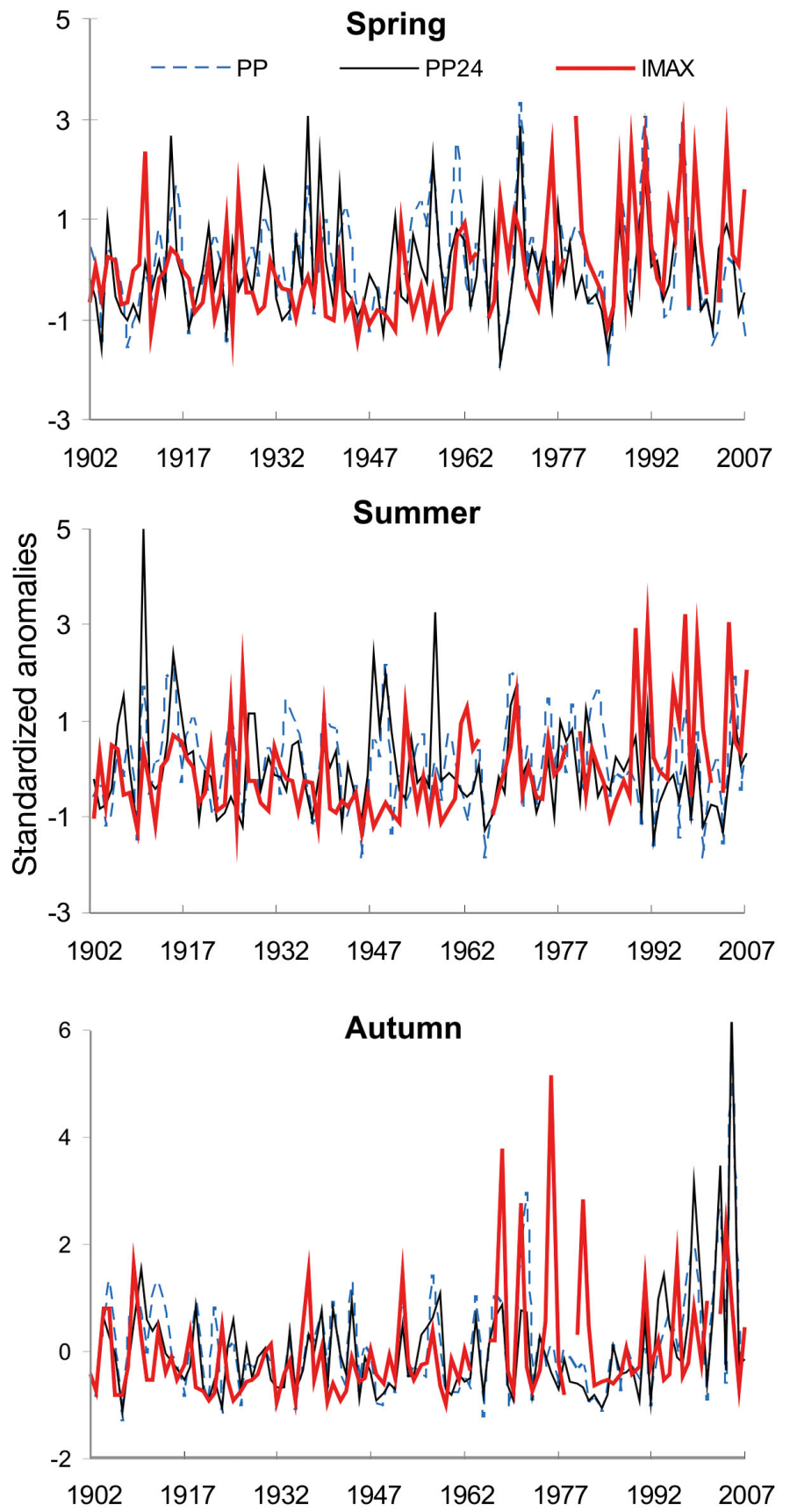

Fig. 2. Comparison between standardized extreme rainfall intensity (IMAX), extreme daily intensity (PP24) and total precipitation amount (PP) at Bucuresti-Filaret station for spring (April-May), summer (June-August) and autumn (September-October)

increase. These findings suggest that the PP and PP24 variability are governed by the same largescale mechanisms (mainly given by the large-scale circulation in spring and autumn and by convection in summer; Busuioc et al. 2010), while for IMAX other mechanisms could be responsible for this behaviour.
One of these mechanisms could be related to $\mathrm{CC}$ scaling, as discussed in the next section. On the other hand, Busuioc et al. (2016) highlighted a shift in the nature of precipitation in Romania towards more showers (high intensity precipitation in a short time), in contrast with no significant increase in the frequency of rainfall days; the mechanism responsible for this behaviour is the combined effect of an increase in atmospheric instability accompanied by more precipitable water in summer and more frequent cyclonic structures crossing Romania in spring. This mechanism could be also responsible for the significant increase of IMAX found in this paper.

On the other hand, statistically significant negative correlation coefficients between IMAX and DIMAX at all stations and the 3 seasons are noted (see Table 3) on shorter (all 6 stations) as well as on longer time series (Bucuresti-Filaret). This result shows an opposite phase between the variability of IMAX and its corresponding DIMAX; namely, shorter durations correspond to a higher intensity of precipitation extremes. Fig. 3 shows, as an example, the temporal variability of IMAX and DIMAX at Bucuresti-Filaret station for spring, summer and autumn. For spring and summer, the long-term trend is not monotonous, showing an upward change point around 1960 (statistically significant at the $5 \%$ level) with IMAX increasing and DIMAX decreasing after this year (in summer a downward shift for DIMAX is recorded around 1987), and an opposite behaviour before but with a weaker negative slope for IMAX.

In conclusion, in comparison with classical indices of fixed duration, the proposed index includes, by definition, the duration associated with the fraction of the highest intensity of a rainfall event. This allows investigation of the characteristics of simultaneous variability for the intensity-duration pair associated with precipitation extremes, namely the connection between these components and possible changes under global warming. Therefore, we could assert that IMAX could be naturally associated with the intensity of extreme precipitation within a rainfall event, shortly named in the following as extreme rainfall intensity, in comparison with precipitation extremes on a fixed temporal scale (daily or hourly).

\subsection{Scaling of extreme rainfall intensity}

Based on the technique presented in Section 2, we investigated the scaling of IMAX highest percentiles (90th, 99th and 99.9th) with daily temperatures at the 6 selected stations in Romania, stratified over the 3 

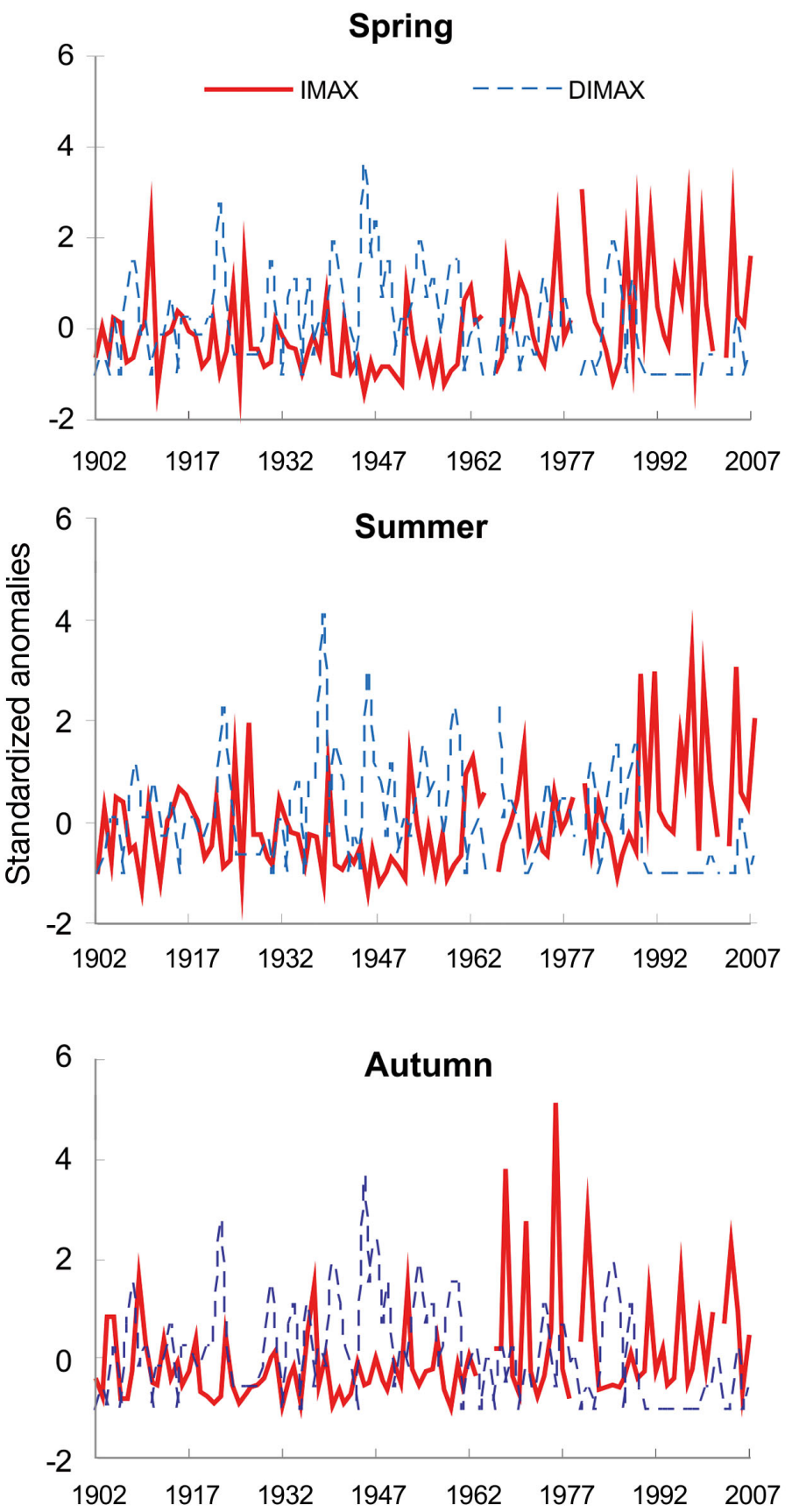

Fig. 3. Comparison between standardized extreme rainfall intensity (IMAX) and corresponding duration (DIMAX) at Bucuresti-Filaret station

seasons (spring, summer and autumn). The results are presented by combining all data over the entire country; the graphic representation of the findings are shown in Fig. 4 (left column), which have been numerically proven by computing the slope of the linear dependence between the natural logarithm of IMAX percentiles and temperature variation (see Annex 1 in the Supplement at www.int-res.com/ articles/suppl/c072p239_supp.pdf) similar to Blenkinsop et al. (2015). The number $(\mathrm{N})$ of events in each temperature bin is summarised in Table S1 in the Supplement. Due to the fact that summer is the wettest season in Romania and autumn is the driest, the highest number of rainfall events used to calculate the IMAX percentiles was recorded in summer (exceeding 3000 events for daily temperatures between 16 and $22^{\circ} \mathrm{C}$ ) and lowest in autumn (the highest number accounting for around 1300 events between 12 and $16^{\circ} \mathrm{C}$ ). In spring and autumn, for temperatures $>20^{\circ} \mathrm{C}$ and $<6^{\circ} \mathrm{C}$ the $\mathrm{N}$ values are small $(<500)$ leading to less precise percentiles. In summer, this situation happens for temperatures $>24^{\circ} \mathrm{C}$ and $<12^{\circ} \mathrm{C}$. However, to assess high quality 99.9th percentiles, $\mathrm{N}$ should be 1000 or more, which is the case for the temperature range of $8-18^{\circ} \mathrm{C}$ in springautumn and $14-24^{\circ} \mathrm{C}$ in summer (see Table S1).

Our results show that the IMAX scaling behaviour depends on season and percentiles, and it is not uniform over the temperature range. In summer, the 90th and 99th percentiles show approximately a CC scaling for the temperature range $14-26^{\circ} \mathrm{C}$, and then decrease. The 99.9th percentile does not exhibit clear scaling, mainly showing a super-CC scaling for temperatures $<18^{\circ} \mathrm{C}$ and then a decrease. The spring and autumn seasons exhibit an almost similar behaviour: the 90th and 99th percentiles show an approximate $2 \mathrm{CC}(12-14 \%)$ scaling for temperatures range of $8-$ $20^{\circ} \mathrm{C}$ (see Annex 1 in the Supplement) with some inflexion points (slope change): for temperatures $>18^{\circ} \mathrm{C}$ the spring 90th percentile follows a CC scaling, while the autumn 90th percentile for temperatures $<12^{\circ} \mathrm{C}$ follows a CC scaling and then a $2 \mathrm{CC}$ scaling; the autumn 99th percentile fits better with $2 \mathrm{CC}$ scaling over the temperature range of $18-24^{\circ} \mathrm{C}$. These details can be very well identified using the numerical computation of the percentile scaling as presented in Annex 1. The dependence of the spring 90th percentile close to $\mathrm{CC}$ scaling for temperatures $>18^{\circ} \mathrm{C}$ has not been revealed in observational studies so far, but it is in agreement with CPM simulations (Singh \& O'Gorman 2014), suggesting that a physical mechanism could be behind this result. However, in this case $\mathrm{N}<1000$. The spring 99.9th percentile exhibits a scaling close to the 2CC relationship (13\%) for a temperature range of $12-18^{\circ} \mathrm{C}$ and then a decrease (but $\mathrm{N}<1000$ ), while the autumn 99.9th percentile exhibits a dependence close to $2 \mathrm{CC}$ scaling for temperatures $<18^{\circ} \mathrm{C}$ and then a scaling close to CC. Since the number of events in spring and autumn is much smaller than that recorded in summer (see Table S1) due to the shortness of these seasons considered in this study 

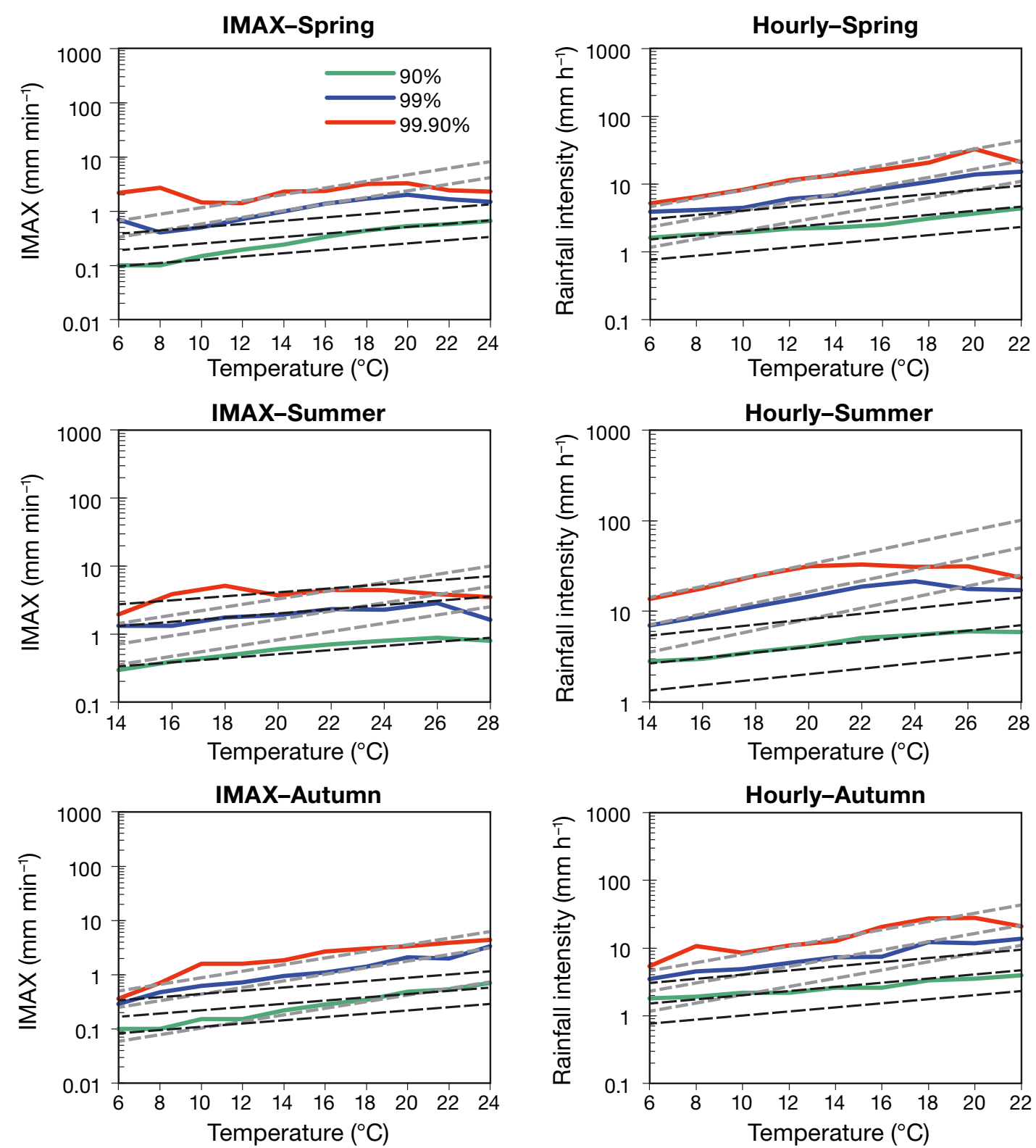

Fig. 4. Scaling of observed extreme rainfall intensity (IMAX; left) and hourly extremes (right) with temperature for 6 stations mixed up together. Shown are different percentiles (90th to 99.9th) of IMAX and hourly extreme distribution for each temperature bin. The Clausius-Clapeyron (CC) and 2CC scalings are presented through the black and grey dashed lines, respectively. Due to the logarithmic $y$-axis these exponential relations are shown as straight lines

(only 2 months as presented in Section 2) on the one hand, and the dry precipitation regime in autumn in Romania on the other hand, we could suspect that the results found for these seasons are less certain. To remove this suspicion, the IMAX data for the 2 seasons were mixed up and the scaling results presented in Fig. S2 in the Supplement. The results show similar behaviour to those presented above separately for spring and autumn, which means results are robust for those 2 seasons. To determine if possible human errors in the delimitation of intervals with constant in- tensity could affect the final results on CC-scaling, an analysis of the scaling behaviour on a station scale but with all data pooled together (from April-October) was carried out. For the Bucuresti-Filaret station, the short (1950-2007) and long periods (1902-2007) were considered. The results (Fig. S3 in the Supplement) show similar behaviour at all stations for each percentile, and are not overly dependent on the time series length. Therefore, we conclude that our results are robust and are not significantly influenced by possible human errors. 
In conclusion, our results show a clear difference between the IMAX scaling behaviour in the summer season (representative of convective rainfalls) and spring/autumn (representative of stratiform rainfalls). Such a difference has also been reported by other studies but with different conclusions. For example, according to Berg et al. (2013), stratiform precipitation extremes increase with temperature at an approximately $\mathrm{CC}$ rate without a characteristic scale, while the convective precipitation extremes exceed the $\mathrm{CC}$ rate and show characteristic spatial and temporal scales; however, they did not use a seasonal stratification as other studies have done (Ban et al. 2015, Blenkinsop et al. 2015). Other recent studies (Westra et al. 2014, Molnar et al. 2015, O'Gorman 2015) highlighted that the relationship between precipitation extremes and temperature is much more complex than suggested by the $\mathrm{CC}$ relationship and is mainly dependent on factors such as temporal resolution, region, local and regional effects (e.g. orography) as well as changes in large-scale forcing. Such conclusions could also be valid in our case: namely, the $\mathrm{CC}$ scaling behaviour for predominant convective precipitation extremes in summer and 2CC scaling behaviour for predominant stratiform precipitation extremes in spring and autumn could be the result of the combined effect of other mechanisms specific to the Romanian area, as Busuioc et al. (2016) revealed. The combined effect of increased atmospheric instability covering Romania accompanied by more precipitable water in summer is the main mechanism responsible for the increase of summer rain shower frequency, while increased atmospheric instability in spring accompanied by changes in atmospheric circulations is responsible for the increase of spring rain shower frequency. On the other hand, the 2CC scaling rate found in spring and autumn could also be explained by a mixture of stratiform and convective precipitation (specific to the Romanian climate in these seasons) that could exaggerate the extreme precipitation-temperature relationship (Berg \& Haerter 2013, Molnar et al. 2015). We must note that the rainfall events in our case are not strictly stratified in terms of storm type as Berg et al. (2013) carried out, and stress that the convective character of Romanian precipitation in summer and the stratiform one in spring and autumn is only a dominant feature; a mixture between the 2 types is possible, with the prevalence of one or the other depending on season. Future research based on storm type stratification of IMAX data and more stations are needed, among other factors, to find a more consistent ex- planation from a physical point of view of the results found in this study.

To see the influence of the duration of precipitation extremes on their relation with temperature, the results of this study are compared to those presented by Busuioc et al. (2016) referring to fixed durations (hourly and daily) of precipitation extremes recorded at the same stations. In this respect, considering the entire annual period with liquid precipitation (for which the hourly precipitation amounts are derived from pluviograph records) with an analysis conducted on a station scale, they found that the 90th percentile shows an approximate CC scaling for all temperatures, while the hourly 99th and 99.9th percentiles follow an almost $2 \mathrm{CC}$ scaling for the temperature range of $10-22^{\circ} \mathrm{C}$ and then a decrease. The daily precipitation extremes do not exhibit a clear scaling behaviour. In order to carry out a correct comparison with our results, the hourly precipitation amounts have been stratified in similar seasons as presented in this study and the results are presented in Fig. 4 (right column) for comparison. The number (N) of events in each temperature bin is summarised in Table S1 in the Supplement. As we can see, N values are much higher than those referring to IMAX events. The results for hourly precipitation extremes, seasonally stratified, are quite similar to those obtained for the extended period (April-October) as presented above, with some seasonal differences: the 90th percentile exhibits a CC scaling behaviour for all temperatures in all analysed seasons; the 99th percentile exceed the CC (close to 2CC) scaling for spring $\left(10-20^{\circ} \mathrm{C}\right)$, summer $\left(14-22^{\circ} \mathrm{C}\right)$ and autumn $\left(10-18^{\circ} \mathrm{C}\right)$ and follows the $\mathrm{CC}$ scaling for temperatures below $10^{\circ} \mathrm{C}$ (spring); the 99.9th percentile exhibits a $2 \mathrm{CC}$ scaling for spring $\left(8-20^{\circ} \mathrm{C}\right)$, summer $\left(14-20^{\circ} \mathrm{C}\right)$ and autumn $\left(10-18^{\circ} \mathrm{C}\right)$.

Difference in scaling behaviour of the extreme rainfall intensity conducted on rainfall events (1 min temporal scale) as proposed in this study (represented by the IMAX percentiles) and corresponding extreme precipitation intensity on hourly scale can be revealed. The most important differences are identified in the behaviour of the 90th percentile (moderate extremes) for the spring and autumn seasons: IMAX exhibits an almost 2CC scaling, in contrast to hourly extremes that follow a CC scaling. This result suggests that the moderate extremes (90th percentile) on the temporal scale proposed in this study $\left(\mathrm{mm} \mathrm{min}^{-1}\right)$ are more sensitive to temperature increase than hourly extremes. The scaling behaviour of the 99th percentile is quite similar for the 2 temporal scales (Fig. 4) in the spring and autumn seasons 
(an almost 2CC scaling) and different in summer: CC scaling for IMAX over the temperature range 14$26^{\circ} \mathrm{C}$ then a decrease; $2 \mathrm{CC}$ scaling for hourly precipitation over the temperature range $14-22^{\circ} \mathrm{C}$ then a decrease. This result shows that for temperatures between 22 and $26^{\circ} \mathrm{C}$, IMAX is more sensitive to temperature increase than the hourly extremes (CC scaling for IMAX and a decrease for hourly precipitation); the $2 \mathrm{CC}$ scaling below $22^{\circ} \mathrm{C}$ for hourly precipitation could be explained by the fact that at this temporal scale the convective precipitation could be mixed with the stratiform ones that may exaggerate the extreme precipitation-temperature relationship (Berg \& Haerter 2013, Molnar et al. 2015).

Therefore, it can be concluded that the magnitude of the CC scaling in Romania is mainly dependent on storm duration, storm intensity and season, in agreement with other studies (Hardwick-Jones et al. 2010, Panthou et al. 2014, Wasko et al. 2015). However, some details in the $\mathrm{CC}$ scaling mentioned above are specific to the Romanian area, that could be explained by an additional influence of other regional factors such as an increase in atmospheric instability covering Romania simultaneously with more frequent cyclonic southern circulations crossing this area in spring and more precipitable water in summer (Busuioc et al. 2016). Future research is needed to analyse in more detail the direct dependence between the scaling of extreme precipitation intensity with temperature in connection with other factors.

\section{CONCLUSIONS}

A new index (IMAX) quantifying the maximum rain intensity within a rainfall event was proposed in this study. IMAX values and their corresponding durations (DIMAX) at 6 stations in Romania, seasonally stratified (spring, summer and autumn), were analysed in 2 ways corresponding to the main 2 objectives of this paper. The main conclusions are summarised in the following.

Our results revealed a robust climate signal over the entire country referring to an opposite phase between the variability of IMAX and its corresponding DIMAX (e.g. shorter durations correspond to higher intensities).

A statistically significant increase of IMAX over the 20th century (intensified over the second half) was found, in contrast with no significant trend for PP24 and PP. Different long-term variability behaviour of IMAX in contrast to PP and PP24 was revealed. This conclusion is supported by analysis of the correlation coefficient between IMAX and PP/PP24. These findings suggest that the variability in PP and PP24 is governed by the same large-scale mechanisms, while for IMAX variability, other mechanisms could be responsible. One mechanism could be related to a shift in the nature of precipitation in Romania towards more showers (high intensity precipitation in a short time), justified by the combined effect of increase in atmospheric instability over Romania accompanied by more precipitable water in summer and more frequent cyclonic structures in spring (Busuioc et al. 2016). An additional factor could be a higher IMAX sensitivity to temperature increase in contrast to PP24, as was proven in this study by the analysis of IMAX scaling.

The IMAX scaling behaviour depends on the season and storm intensity and varies over the temperature range. In summer, the 90th and 99th percentiles followed an approximate CC scaling for the temperature range $14-26^{\circ} \mathrm{C}$. The 99.9th percentile (rare events) did not exhibit clear scaling, mainly showing a super-CC scaling for temperatures lower than $18^{\circ} \mathrm{C}$ and then a decrease. The spring and autumn 90th and 99th percentiles showed an approximate 2CC scaling for a temperatures range of $8-20^{\circ} \mathrm{C}$. The 99.9th percentile exhibited a scaling close to the $2 \mathrm{CC}$ relationship for a temperatures range of $12-18^{\circ} \mathrm{C}$ (spring) and then a decrease, while the autumn 99.9th percentile exhibited a dependence close to $2 \mathrm{CC}$ scaling for temperatures $<18^{\circ} \mathrm{C}$ and then a scaling close to CC.

Comparing these results with those referring to hourly and daily precipitation extremes (Busuioc et al. 2016), we can conclude that the magnitude of the CC scaling in Romania is mainly dependent on the temporal scale of the extreme precipitation event, storm intensity and season, as previous studies have revealed (Hardwick-Jones et al. 2010, Westra et al. 2014, O'Gorman, 2015). The proposed IMAX index is more sensitive to temperature increase than the hourly and daily extremes, and therefore it is more appropriate to quantify the climate signal related to intense precipitation events in a warmer climate.

All these results are in agreement with the main conclusion presented in recent review papers (Westra et al. 2014, O'Gorman 2015); that the relationship between precipitation extremes and temperature is much more complex than suggested by the CC relationship, and that it is dependent on many factors, some of them being considered in this study for Romania. Future research is needed for Romania to analyse in more detail the direct influence of other factors such as storm type, complex Romanian orography, etc. 
Acknowledgements. This study was funded by the Executive Agency for Higher Education, Research, Development and Innovation Funding (UEFISCDI) through the research project CLIMHYDEX, code PNII-ID-2011-2-0073 (http://climhydex. meteoromania.ro). Three anonymous reviewers are acknowledged for their very useful comments, which considerably improved the original manuscript.

\section{LITERATURE CITED}

Allan RP, Soden BJ (2008) Atmospheric warming and the amplification of precipitation extremes. Science 321: 1481-1484

Ban N, Schmidli J, Schär C (2015) Heavy precipitation in a changing climate: Does short-term summer precipitation increase faster? Geophys Res Lett 42:1165-1172

Benestad R (2013) Association between trends in daily rainfall percentiles and the global mean temperature. J Geophys Res Atmos 118:10,802-10,810

Berg P, Haerter JO (2013) Unexpected increase in precipitation intensity with temperature - a result of mixing precipitation types? Atmos Res 119:56-61

Berg P, Moseley C, Haerter JO (2013) Strong increase in convective precipitation in response to higher temperatures. Nat Geosci 6:181-185

Blenkinsop S, Chan SC, Kendon EJ, Roberts NM, Fowler HJ (2015) Temperature influences on intense UK hourly precipitation and dependency on large-scale circulation. Environ Res Lett 10:054021

Busuioc A, Caian M, Cheval S, Bojariu R, Boroneant C, Baciu M, Dumitrescu A (2010) Climate variability and change in Romania. Pro Universitaria, Bucure ti (in Romanian)

Busuioc A, Dobrinescu A, Birsan MV, Dumitrescu A, Orzan A (2015) Spatial and temporal variability of climate extremes in Romania and associated large-scale mechanisms. Int J Climatol 35:1278-1300

Busuioc A, Birsan MV, Carbunaru D, Baciu M, Orzan A (2016) Changes in the large-scale thermodynamic instability and connection with rain shower frequency over Romania: verification of the Clausius-Clapeyron scaling. Int J Climatol 36:2015-2034

Chan SC, Kendom EJ, Roberts NM, Fowler HJ, Blenkinsop S (2015) Downturn in scaling of UK extreme rainfall with temperature for future hottest days. Nat Geosci 9:24-28

Hardwick-Jones R, Westra S, Sharma A (2010) Observed relationships between extreme sub-daily precipitation, surface temperature, and relative humidity. Geophys Res Lett 37:L22805

Kulkarni A, von Storch H (1995) Monte Carlo experiments

Editorial responsibility: Eduardo Zorita,

Geesthacht, Germany on the effect of serial correlation on the Mann-Kendall test of trend. Meteorol Z NF 4:82-85

Lenderink G, van Meijgaard E (2008) Increase in hourly precipitation extremes beyond expectations from temperature changes. Nat Geosci 1:511-514

Kenderink G, Mok HY, Lee TC, Van Oldenborgh GJ (2011) Scaling and trends of hourly precipitation extremes in two different climate zones-Hong Kong and the Netherlands. Hydrol Earth Syst Sci 8:4701-4719

Loriaux JM, Lenderink G, De Roode SR, Siebesma AP (2013) Understanding convective extreme precipitation scaling using observations and an entraining plume mode. J Atmos Sci 70:3641-3655

Molnar P, Fatichi S, Gaál L, Szolgay J, Burlando P (2015) Storm type effects on super Clausius-Clapeyron scaling of intense rainstorm properties with air temperature. Hydrol Earth Syst Sci 19:1753-1766

*'Gorman PA (2015) Precipitation extremes under climate change. Curr Clim Change Rep 1:49-59

* Pall P, Allen MR, Stone DA (2007) Testing the ClausiusClapeyron constraint on changes in extreme precipitation under $\mathrm{CO}_{2}$ warming. Clim Dyn 28:351-363

* Panthou G, Mailhot A, Laurence E, Talbot G (2014) Relationship between surface temperature and extreme rainfalls: a multi-timescale and event-based analysis. J Hydrometeorol 15:1999-2011

Pettitt AN (1979) A non-parametric approach to the changepoint problem. Appl Stat 28:126-135

* Prein AF, Langhans W, Fosser G, Ferrone A and others (2015) A review on regional convection-permitting climate modeling: demonstrations, prospects, and challenges. Rev Geophys 53:323-361

Scoccimarro E, Gualdi S, Bellucci A, Zampieri M, Navarra A (2013) Heavy precipitation events in a warmer climate: results from CMIP5 models. J Clim 26:7902-7911

* Singh MS, O'Gorman PA (2014) Influence of microphysics on the scaling of precipitation extremes with temperature. Geophys Res Lett 41:6037-6044

* Trenberth KE, Dai A, Rasmussen RM, Parsons DB (2003) The changing character of precipitation. Bull Am Meteorol Soc 84:1205-1217

*Wasko C, Sharma A (2015) Steeper temporal distribution of rain intensity at higher temperatures within Australian storms. Nat Geosci 8:527-529

ㄴ Wasko C, Sharma A, Johnson F (2015) Does storm duration modulate the extreme precipitation-temperature scaling relationship? Geophys Res Lett 42:8783-8790

*Westra S, Fowler HJ, Evans JP, Alexander LV and others (2014) Future changes to the intensity and frequency of short-duration extreme rainfall. Rev Geophys 52:522-555

Submitted: August 13, 2016; Accepted: April 10, 2017 Proofs received from author(s): June 16, 2017 